\title{
Comprehensive Evaluation Study of the Owners under the General Contracting Mode of the Project
}

\author{
GUO Rui ${ }^{1, *}$, Liu Xiao dong ${ }^{2}$, Zhu $\mathrm{Pu}^{3}$, Zhang Jing ${ }^{4}$, Yang Chun $\operatorname{lin}^{5}$ \\ ${ }^{1}$ School of Equipment Management and UAV Engineering, Air Force Engineering University, Xi an, Shan xi province \\ ${ }^{2}$ School of Equipment Management and UAV Engineering, Air Force Engineering University, Xi an, Shan xi province \\ ${ }^{3}$ School of Equipment Management and UAV Engineering, Air Force Engineering University, Xi an, Shan xi province \\ ${ }^{4}$ School of Equipment Management and UAV Engineering, Air Force Engineering University, Xi an, Shan xi province \\ ${ }^{5}$ School of Equipment Management and UAV Engineering, Air Force Engineering University, Xi an, Shan xi province
}

\begin{abstract}
How do owners balance the management and encouragement of general contractors under EPC mode not only affect the project construction effect, but also hinder the promotion of EPC mode. Referring to the theory of evaluation and the thought of performance evaluation, this paper puts forward a set of novel comprehensive evaluation methods from five aspects: comprehensive evaluation index system, comprehensive evaluation method system, grading rules, method and index weighting and comprehensive evaluation. Through the construction of a reasonable comprehensive evaluation framework, it aims to coordinate the commonly used management forces and means of existing engineering construction, objectively and reasonably evaluate the general contractor's behavior and project construction effect, solve the practical problem of difficult owner supervision under EPC mode, and promote the popularization and application of EPC mode in China.
\end{abstract}

\section{Introduction}

Adopting EPC model has the advantages of reducing owner's risk and improving construction efficiency ${ }^{[1]}$, but in the face of the situation that the management "center" status is no longer the case, how to ensure that the finished building is in agreement with construction demand, how to balance the supervision and encouragement of the general contractor and other issues still need to continue to study and optimize ${ }^{[2][3]}$. At present, the research on owner-side management under EPC mode mainly focuses on how the industry can do a good job in managing the

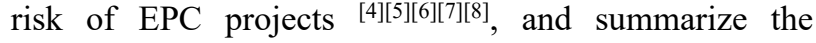
management experience in the light of engineering cases [9][10][11]. In addition, reference [3] from the scope management of the general contracting project, the selection of the contracting mode and the optimization of the bidding procedures, to help the owners do a good job in the early planning work. Reference [12] through the establishment of the analysis of the EPC model of the principal agent model, put forward the general contractor to work the owner's behavior proposals, and from the cost, schedule and other aspects of the establishment of the general contractor behavior evaluation mechanism for the owners to provide the basis for the next choice of contractors. Reference [13] from business, technology and management three major selection indicators to build a comprehensive evaluation system to help the owner unit to choose the most suitable general contractor. Reference [14] believes that the owner should focus on doing a good job in the design task book to ensure the smooth progress of the project later. Reference [15] from the perspective of the relationship between the owner and general contractor to improve the project management performance, the results show that the relationship governance trust, commitment, communication and practice four factors can effectively promote cooperation between the two sides, improve project management performance.

Existing research can help the owners to select and manage the EPC general contractor in some respects, but the lack of general management methods from the construction practice of the owners, easy to implement and cover a wider range of general management methods to effectively supervise the general contractor and its construction behavior, project construction process and construction results. Based on the above considerations, the paper puts forward an EPC model of the owners of the general contractor and construction projects comprehensive evaluation management methods, including evaluation index system, evaluation method system and other content, the general contractor and its construction behavior, project construction process and construction results to achieve comprehensive evaluation coverage, which aimed at helping the owners to effectively supervise the general contractor and construction projects, and help to promote the use of EPC model in China's construction industry.

*E-mail: supergr010925@163.com Tel:15308965260 


\section{Owner's performance evaluation in EPC mode}

Under the EPC model, the owner authorizes the general contractor to have a higher degree of autonomy on the basis of contract and trust, in order to encourage the general contractor to develop the project with professional expertise and efficiency. However, due to the incomplete transaction contract, information asymmetry and other issues, the owner must take appropriate measures to manage the transaction process, to protect the interests of the most important ${ }^{[2]}$. In practice, in order to balance the encouragement and supervision of the general contractor, the owner usually adopts the method of performance evaluation to manage the general contractor, that is, under the constraints of the contract and existing building regulations, combined with the actual setting of the corresponding inspection standards, inspection means and inspection nodes, to achieve the management of the general contractor and its construction behavior.

\section{New comprehensive evaluation method of owners under EPC mode}

In order to realize the goal of more reasonable performance evaluation of the general contractor under the EPC model, drawing on the objective management of performance management, BSC and dynamic management theory ${ }^{[16]}$, as well as the basic attribute requirements of evaluation of effectiveness, feasibility, applicability, accuracy and evaluation accountability put forward by the evaluation theory ${ }^{[17]}$, the article proposes to construct a set of novel comprehensive evaluation methods from the aspects of index system, evaluation method, scoring rules, weight assignment and comprehensive evaluation, such as the figure 1 .

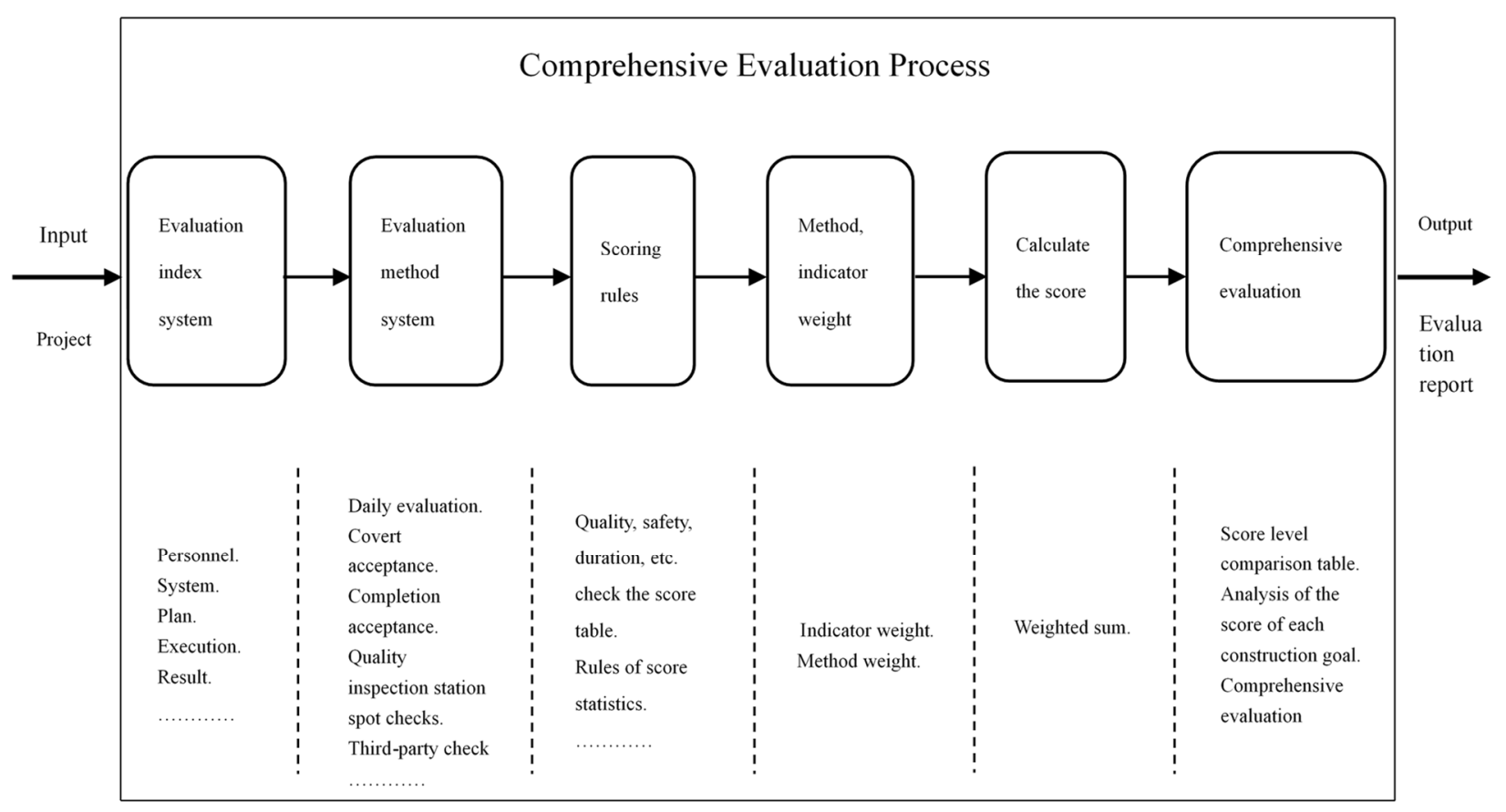

Fig 1. comprehensive evaluation method

\subsection{Build a comprehensive evaluation index system}

Taking into account the functional positioning of the construction enterprise and its project department, the general contractor can be regarded as a system consisting of four aspects: professionals, regulations, work plan and work execution, and based on this consideration, the article chooses to construct a system of evaluation indicators from the five aspects of personnel, system, plan, implementation and results to conduct a comprehensive evaluation of the general contractor and construction projects, such as Table I. The comprehensive evaluation of the general contractor and construction project by the owners is divided into the formation evaluation and the summary evaluation.

\subsubsection{Formative evaluation}

The owners conduct a comprehensive evaluation of the general contractor and his project department through four aspects: personnel, system, plan and implementation, in order to master their organizational management and execution capabilities and ensure the quality of the process of construction. Through the project organization set up, the number of personnel, professional, qualification and so on to evaluate the personnel, to ensure that the investment of professional strength to meet the project construction needs. Through the general contractor around the project construction of various types of organizations, management systems and design, construction plans, etc. are complete, evaluate its organizational management level, to ensure that the project construction organization 
is efficient, nodes clear. Implementation includes both system implementation and plan implementation, the results of system implementation can be evaluated through the organization of operating procedures, drawings, construction quality, and civilized site construction, while the implementation of the plan can be evaluated through milestone node completion, investment completion and personnel, materials, machine input, etc. In addition, the two aspects of the implementation evaluation should also include the implementation of records, such as concealed engineering acceptance records, equipment out-of-thebox records and records of examine the drawings and deliver the design. The three-level indicators in Table I can be supplemented in practice by combining the actual project.

Table1. Under the EPC model, the owner's comprehensive evaluation index system for Party B and construction projects

\begin{tabular}{|c|c|c|c|}
\hline $\begin{array}{l}\text { The target } \\
\text { layer }\end{array}$ & $\begin{array}{l}\text { Level one } \\
\text { indicators }\end{array}$ & $\begin{array}{l}\text { Level two } \\
\text { indicators }\end{array}$ & Level three indicators \\
\hline \multirow{22}{*}{$\begin{array}{l}\text { Comprehen- } \\
\text { sive } \\
\text { evaluation } \\
\text { of the EPC } \\
\text { project }\end{array}$} & \multirow{17}{*}{$\begin{array}{l}\text { Formative } \\
\text { evaluation }\end{array}$} & \multirow{2}{*}{ Personnel } & Organizational Structure \\
\hline & & & $\begin{array}{l}\text { Number of Personnel and } \\
\text { Qualifications }\end{array}$ \\
\hline & & \multirow{4}{*}{ System } & Organizational system \\
\hline & & & Management system \\
\hline & & & Technical system \\
\hline & & & Economic \\
\hline & & \multirow{4}{*}{ Plan } & $\begin{array}{l}\text { The overall schedule of the } \\
\text { construction of the project }\end{array}$ \\
\hline & & & Engineering design schedule \\
\hline & & & Material procurement schedule \\
\hline & & & Project construction schedule \\
\hline & & \multirow{7}{*}{ Execution } & $\begin{array}{l}\text { Construction of safe and } \\
\text { civilized construction sites }\end{array}$ \\
\hline & & & Construction quality \\
\hline & & & The quality of the drawings \\
\hline & & & Completion of the investment \\
\hline & & & Milestone node implementation \\
\hline & & & People, materials, machine input \\
\hline & & & Execute the record \\
\hline & \multirow{5}{*}{$\begin{array}{l}\text { Summary } \\
\text { evaluation }\end{array}$} & \multirow{5}{*}{ Results } & Completion of quality objectives \\
\hline & & & $\begin{array}{l}\text { Completion of investment } \\
\text { objectives }\end{array}$ \\
\hline & & & $\begin{array}{l}\text { The completion of the duration } \\
\text { target }\end{array}$ \\
\hline & & & Safety liability accidents \\
\hline & & & Outstanding contribution \\
\hline
\end{tabular}

\subsubsection{Summary evaluation}

Summary evaluation can be a phased or final result evaluation, which mainly evaluates the comprehensive quality of engineering construction results in terms of project quality, progress, cost, safety and outstanding contribution. As shown in Table I, the quality, investment, duration and safety management evaluation of the project is mainly reflected through the phased or completed project construction results, such as through the completion of the milestone node to evaluate the quality of the project up to the node, progress, investment completion and safety management, etc., can also be through the project completion acceptance results to check its completion, to reflect the overall quality of the final construction results of the project. Outstanding contribution refers to whether the project management objectives of the project are over-fulfilled, such as the project ahead of schedule more than $15 \%$, compressed investment of more than $10 \%$, or the project won the China Construction Engineering Luban Prize and other important awards, this part of the content can be clearly defined in the general contract.

\subsection{A comprehensive evaluation method system}

In order to avoid the problem of incomplete one-time evaluation and large subjective randomness, the evaluation method system will closely follow the actual construction of the project, with the help of the engineering participation units, third-party independent testing units and government quality supervision departments and other multi-party forces, overall consideration of daily inspection evaluation, sampling evaluation and acceptance evaluation and other multilevel multi-dimensional evaluation results, so that the final evaluation results more objective, rational, but also closer to the real situation of the project construction. The comprehensive evaluation method system includes the following four specific evaluation methods.

\subsubsection{The daily inspection and evaluation of the owner, the whole process consultation and supervision}

When using EPC mode, in order to maximize the initiative of the general contractor and give full play to its professional expertise, the depth and frequency of the owner's management of construction projects is far lower than the traditional management model. Owner units and consulting units, supervision units should formulate a project inspection and evaluation plan, such as the monthly irregular inspection once, and do a good job of daily inspection.

\subsubsection{Process acceptance, completion acceptance inspection evaluation}

Process acceptance includes drawing review and project covert acceptance, handover acceptance, etc., through the acceptance results to evaluate the quality of the project in the construction process.

\subsubsection{Commission a third-party check}

Entrusting a third party to conduct a comprehensive or special inspection of the project is a common method in the management of construction projects, the main purpose of which is to evaluate the quality and management of the project construction through independent third-party institutions, analyze and find 
management loopholes or weaknesses, and promote the continuous optimization of the construction and management of the project by participating units.

\subsubsection{Supervision station inspection and evaluation}

Quality supervision station inspection is in accordance with the requirements of building regulations of the government building authorities to supervise the quality of construction measures, through the quality supervision station from time to time sampling, to help government departments to grasp the general situation of project construction.

\subsection{Scoring rules}

After the establishment of the project management team, the owners organize the general contractor, consulting units and supervision units to jointly study and refine the comprehensive evaluation method in line with the actual situation of the project, mainly on the indicator system of the three-level indicators, scoring rules, inspection and scoring tables, etc. as appropriate to adjust and improve, so that it is scientific and reasonable, with operability. Space is limited, the article can not be listed in the various inspection scoring tables, but the main scoring, scoring rules to study, build a scoring framework, in order to all kinds of inspection scoring results into the comprehensive evaluation of the project.

- All three-level indicators should be evaluated in accordance with the relevant construction norms to develop the corresponding control checklist, easy to guide the evaluation, score. In Table I, except the outstanding contribution of the initial score of 0 points, when there is outstanding contribution plus points, the remaining indicators of the initial score of 100 points, found that the problem according to the control checklist requirements corresponding subtract.

- For some secondary indicators of the formative evaluation has too many sub-indicators, if the use of item-by-item score, empowerment after the settlement of the situation, there will be an unable to accurately empower them, and therefore can be taken to find an average point approach to solve. If there are 20 sub-indicators under the system indicators, the inspection team can pass the overall score after the inspection and evaluation of whether the system is complete, whether the quality of the system is qualified, whether the system is systematic, etc., and then calculate the average score of the inspectors as the final score. The remaining indicators should be empowered on a case-by-case basis, with a score-by-score approach.

- Owners, consulting firms and supervisors should formulate daily management inspection plans, such as once a month, so that you can know the total number of inspections in order to obtain the final average score of a certain indicator. If there are supervision and consulting company inspection is more frequent, and a certain inspection may be a special inspection of the situation, you can set a cycle, such as 1 month, the period of time for one or more of the above indicators of the score of statistics, average, recorded as the evaluation score of each project for the month. The three unit scoring points can be used for evaluation alone, or according to certain rules such as owners, consulting companies and supervision units are empowered $0.4,0.3,0.3$ to the three units scoring results combined calculation and then the enterprise evaluation.

- Consider the comprehensive evaluation cycle is longer, involving many units, so should do a good job of daily records. First of all, when the daily inspection, the inspection unit should find problems and deduction of points in writing contact form to formally notify the responsible unit, and copy the relevant units, as the final score voucher; Secondly, the quality supervision station and third-party inspection of the discovery of problems and deduction of points should be sent to the owner in official documents, and by the owner copied to the relevant units. Finally, when the process acceptance and completion acceptance, the current project should be evaluated five major scoring items, and in the acceptance report raised questions and deductions issued to each unit.

\subsection{Determine the weight}

Determines that the weights include metric weights and method weights. The comprehensive evaluation results are more reasonable by the relevant experts and participating units of the owner's organization at the beginning of the project, and at the same time, the owners can adjust the various indicators and methods according to their management preferences within a reasonable range.

1) Indicator weight, that is, the weight of indicators at all levels in the comprehensive evaluation index system. Indicator empowerment mainly considers the importance of indicators to the overall quality composition of construction projects. This article temporarily empowers the first and second-level indicators as table II.

2) Method weight, that is, the weight of the above evaluation methods. Method weight mainly considers the importance of various inspection methods to promote the general contractor to improve the quality of project construction, and takes into account the timeliness of inspection methods, such as quality supervision station inspection, although important, but its limited number of inspections, the promotion of engineering construction is not as good as the owners, supervisors and consulting companies of the day-to-day inspection. The tentative method weights in this paper are such as Table III. 
Table2. Weight table for evaluation indicators

\begin{tabular}{|c|c|c|c|c|}
\hline Level one indicators & Weight & $\begin{array}{l}\text { Level two } \\
\text { indicators }\end{array}$ & & Weight \\
\hline \multirow{4}{*}{$\begin{array}{c}\text { Process evaluation } \\
\eta_{1}\end{array}$} & \multirow{4}{*}{0.4} & Personnel & $\omega_{1}$ & 0.3 \\
\hline & & System & $\omega_{2}$ & 0.2 \\
\hline & & Plan & $\omega_{3}$ & 0.2 \\
\hline & & Execution & $\omega_{4}$ & 0.3 \\
\hline $\begin{array}{c}\text { Summary evaluation } \\
\eta_{2}\end{array}$ & 0.6 & Results & $\omega_{5}$ & 1 \\
\hline
\end{tabular}

Table3. Weight table for evaluation methods

\begin{tabular}{|l|c|c|}
\hline Check the method & Code & Weight \\
\hline Daily inspection & $\mu_{1}$ & 0.3 \\
\hline Process, completion acceptance & $\mu_{2}$ & 0.3 \\
\hline Third-party checks & $\mu_{3}$ & 0.2 \\
\hline $\begin{array}{l}\text { Quality supervision station } \\
\text { inspection }\end{array}$ & $\mu_{4}$ & 0.2 \\
\hline
\end{tabular}

\subsection{Comprehensive evaluation}

\subsubsection{Calculate the score}

\subsubsection{Determine the scoring results}

Given the long project construction cycle and the high number of inspection units and inspections, score approval should be carried out before the score is calculated to determine the score results for each indicator. This is done by the owners, supervisors, consulting firms and general contractors combing through the retained inspection score contact forms and compiling a summary of inspection scores containing items such as inspection units, inspection items, inspection time, inspection scores, etc.;

\subsubsection{Calculate the score}

According to the evaluation index model, scoring rules and corresponding indicators and method weights, the final score is calculated by means of weighted aggity.

$$
\begin{aligned}
& F=\eta_{1} *\left(\sum_{j=1}^{4} \omega_{j}\left(\sum_{i=1}^{4} \mu_{j i} * f_{j i}\right)\right)+\eta_{2} *\left(\omega_{5} *\right. \\
& \left.\left(\sum_{i=1}^{4} \mu_{j 5} * f_{j 5}\right)\right) \quad(j=1,2, \ldots 5, \quad i=1,2 \ldots 4)
\end{aligned}
$$

The final score for the evaluation of the project by $f_{j i}$ for each inspection method.

\subsubsection{Rating}

Set up a score level comparison table to determine the comprehensive evaluation level corresponding to the comprehensive score of the general contractor and construction project to be evaluated. The score level control table also requires the owner to invite relevant experts and participating units to study and determine at the beginning of the project. This paper tentative score level control table such as Table IV.
Table4. Comprehensive evaluation score level comparison table

\begin{tabular}{|c|c|c|c|c|}
\hline Grade & Excellent & Good & Qualified & Not qualified \\
\hline Score & $90-100$ & $80-89$ & $60-79$ & Below 60 \\
\hline
\end{tabular}

\subsubsection{Evaluation report}

After evaluating the general contractor and construction projects according to the comprehensive evaluation method, a comprehensive evaluation report should be formed. The evaluation report should include a multifaceted evaluation of the general contractor and construction project based on the secondary indicators, a multi-view evaluation of the general contractor and construction project based on the units of the four evaluation methods, and a comprehensive evaluation conclusion of the project. The content mainly includes: the evaluation of various sides and perspectives should include the highlights, shortcomings and suggestions of the general contractor and the construction project, and the comprehensive evaluation should include the degree to which the project meets the requirements of the contract documents, as well as the comprehensive evaluation grade of the project. Through the evaluation report, we summarize the problems in the construction of the project, study the improvement measures, and promote the further improvement of the construction and comprehensive evaluation of the project.

\subsection{Description of the application of the comprehensive evaluation method}

The EPC model of owners' comprehensive evaluation of general contractors and construction projects is designed to help owners balance the contradictions of "effective supervision" and "over-management". Evaluation method upholds the idea of results-oriented, more attention to process management, the results require reverse process management, pay attention to process quality to ensure the quality of results, so that the owner unit in the new model of management work has a grasp, there is a law.

- The evaluation system has no professional ability or technical evaluation, mainly considering that the tender has been the enterprise qualification and project participation experience and other corresponding requirements, can be considered that the general contractor has the corresponding professional ability.

- The comprehensive evaluation method does not distinguish between special inspection and comprehensive inspection, such as safety special inspection, quality special inspection, etc., mainly consider two points: First, if a comprehensive inspection is carried out, the construction project can be comprehensively evaluated according to the evaluation system; second, if special inspections such as safety inspection are carried out, the contents of the inspection will involve full-time safety personnel, 
safety management system, safety management plan, implementation of safety system and plan (process evaluation), as well as the safety accident situation (result evaluation) as of the inspection time, can also be used by this evaluation system to conduct a comprehensive evaluation of the safety management of construction projects. In summary, whether for a comprehensive inspection or special inspection, this evaluation system can be applied to help owners from all-round, multi-angle comprehensive evaluation of enterprises.

- There are two preconditions for the application of comprehensive evaluation methods, one is the perfect evaluation procedure, strict organization, document standards, and the other is the recognition of building regulations. Therefore, in addition to the evaluation index system, evaluation methods, weight assignment, etc. mentioned above can be combined with the actual adjustment and improvement of construction projects, the remaining evaluation organizations, check the score sheet, evaluation contact list, as well as the final evaluation report should have relatively fixed procedures and formats, and in line with the existing building regulations, so that it can be used among the parties involved in the construction.

- There is no reward and punishment measures are proposed this paper, mainly considering that the current EPC model is still being explored, the implementation process may encounter a variety of unpredictable circumstances, coupled with the implementation of incentives and the subjective preferences of the owners have a greater relationship, so it is recommended that each project owner units to study and determine their own.

\section{Case study}

Owner ZJ Company opened the tender for the M project under the EPC general contracting model and signed a general contract with the winning GQ company for a period of 16 months. The owner unit components 3 owners project department, and commissioned supervision company L, construction consulting company $\mathrm{ZZ}$ to manage the project, formed by the "owner and consulting company and supervision" management team. At present, the project has been completed, through the project since the construction of various evaluation documents to collect, classify, the results such as Table V.

Table5. Project M Comprehensive Evaluation Statistics Table

\begin{tabular}{|l|c|c|l|l|}
\hline & $\begin{array}{l}\text { Daily } \\
\text { inspection }\end{array}$ & $\begin{array}{l}\text { Acceptance } \\
\text { inspection }\end{array}$ & $\begin{array}{l}\text { Third- } \\
\text { party } \\
\text { detection }\end{array}$ & $\begin{array}{l}\text { Quality } \\
\text { supervision } \\
\text { station } \\
\text { inspection }\end{array}$ \\
\hline Personnel & 87 & 91 & 86 & 93 \\
\hline
\end{tabular}

\begin{tabular}{|c|c|c|c|c|} 
System & 85 & 89 & 87 & 83 \\
\hline Plan & 89 & 92 & 86 & 84 \\
\hline Execution & 80 & 81 & 85 & 87 \\
\hline Results & 78 & 75 & 82 & 80 \\
\hline
\end{tabular}

According to the indicators and methods of Tables 2 and 3 , the comprehensive score of the $\mathrm{M}$ project can be calculated in combination with equation (1).

$$
\begin{aligned}
& F=\eta_{1} *\left(\sum_{j=1}^{4} \omega_{j}\left(\sum_{i=1}^{4} \mu_{j i} * f_{j i}\right)\right)+\eta_{2} *\left(\omega_{5}\right. \\
& \left.*\left(\sum_{i=1}^{4} \mu_{j 5} * f_{j 5}\right)\right) \\
& =0.4 *(26.8+17.2+17.7+24.8)+0.6 * 78.3 \\
& =81.6
\end{aligned}
$$

According to Table 4, the overall rating of the general contractor and the construction project in project $M$ is good. At the same time, it can be seen from the evaluation statistics table that although the general contractor in personnel, systems and plans to make reasonable arrangements, but the construction results from the expected objectives there is still a certain gap, should be given more attention at the implementation level.

\section{Conclusion}

This paper regards the enterprise as a system consisting of four parts: personnel, system, plan and implementation, and constructs a comprehensive evaluation index system based on the construction process and results of the project, so as to clarify the evaluation content of the general contractor and construction project by the owners under the EPC model. Secondly, Secondly, combined with the supervision and inspection methods commonly used in the actual construction of the project, the comprehensive evaluation method system is constructed, and all-round evaluation of the general contractor and construction project is carried out from various levels, which ensures that the evaluation results are objective and reasonable, close to the real situation of the general contractor and the construction project. Finally, by constructing a perfect comprehensive evaluation method, it not only helps the owners to realize the effective supervision of construction enterprises under the new model, but also makes the general contractor work under a more perfect supervision system because the evaluation method is formulated by many parties and implemented fairly without hitting the enthusiasm of EPC general contracting.

\section{Acknowledgements}

On-the-job study is a rare opportunity and challenge for everyone who is married and has children, so I am very grateful to my family for their quiet efforts and support behind my back, their encouragement has always been my motivation to move forward. In addition, the erudite and rigorous tutor also provided professional and accurate 
guidance for my academic research, and the students who studied together helped and improved each other, thanks to good teacher-student relations and teamwork, so that I went higher and farther on the road to scientific research, and saw a better scenery.

\section{References}

1. Yu Jin-kun, (2018) The optimization of the spatial structure of EPC and DBB.

https://kns.cnki.net/kcms/detail/detail.aspx?dbcode= CMFD\&dbname $=$ CMFD201901\& filename $=101884$ 6828.nh\&v=ozEz7zUJW9TcpK0gV\%25mmd2F17T f\% $\% 25 \mathrm{mmd} 2 \mathrm{BCTj} \% 25 \mathrm{mmd} 2 \mathrm{FN} \% 25 \mathrm{mmd} 2 \mathrm{~B} 21 \mathrm{Oknb}$ HQrsNrTPHt8gJsVak59xywB1a\%25mmd2FYTW

2. Chen Yan,(2019)Research on EPC Engineering Project Transaction Mode and Innovation Path Based on Value-added Persective. https://kns.cnki.net/kcms/detail/detail.aspx?dbcode= CMFD\&dbname $=$ CMFD202001\& filename $=101960$ 5394.nh\&v=tCPWGPvFzPUNg\%25mmd2F5Y1I2m 2vfzI\%25mmd2FLbj4YYhQzrN5p1 fatBaY3IuU4a6 $\% 25 \mathrm{mmd} 2 \mathrm{FrV} 6 \mathrm{VPAmnI} 5$

3. Chen Qing-hua,(2005)The Study on the Employer's Administration in General Contract Mode. https://kns.cnki.net/kcms/detail/detail.aspx?dbcode $=$ $\mathrm{CMFD} \&$ dbname $=\mathrm{CMFD} 2007 \&$ filename $=20070653$ 62.nh\&v $=\mathrm{kAvww} \% 25 \mathrm{mmd} 2 \mathrm{Fo} 0 \mathrm{iIdQMDys} 1 \mathrm{CR} 3 \mathrm{~J} 5 \mathrm{~F}$ 408NEdzmUFxJ16gYvHGPcR7ty1A\%25mmd2FLF GaIx\%25mmd2BKDOwz6

4. Song Zhi-wei,(2017) Research on Risk Management of Large Hydropower EPC Project in the Tender Stage Based on the Owner's Perspective. https://kns.cnki.net/kcms/detail/detail.aspx?dbcode= CMFD\&dbname $=$ CMFD201901\& filename $=101887$ 6496.nh\&v $=$ dRfjfj1Y6zQ2N7R\%25mmd2B9wWo1 SpbiUJMOHS8JD640Y7hfCMIpdTBKRRhs1Ew3x 0eqtie

5. Zhou Ying,(2006)The research of Owner's Risk Management in the Government-invested Project carrying out Agency Construction Specializing Management Mode.

https://kns.cnki.net/kcms/detail/detail.aspx?dbcode= CMFD\&dbname $=$ CMFD2007\& filename $=20061860$ 75.nh \&v=Rkm5eLOKa5nTqn8OlILUNIW4n5gFCO 0Qhnjyj7RzceHAVrMiWdqCPiWdgQTbf $\% 25 \mathrm{mmd} 2$ $\mathrm{BbA}$

6. Dong Yan-chen, Jiang An-min, and etc.(2018) Research on the Construction and Application of Risk Assessment Model for Overseas EPC Projects. Journal of Engineering Management, 05:103-108.

7. Wang Yi-chuan, Chen Yue-hua and etc.(2018) Research on Risk Analysis of International EPC Projects From the Perspective of Contractors. Journal of Engineering Management, 05:97-102.

8. Gao Hui, Wang Zong-jun,(2016) The General Contractor's Risk Prevention Measures under EPC Mode. Journal of Engineering Management, 01:114119.
9. Song Gui-qi,(2015) The Audit of Engineering Tracking in EPC Mode is Discussed. Chinese \& Foreign Entrepreneurs, 36:60-62.

10. Tian Zhi-zhong,(2019) Risk Control for Owners of Large-scale Engineering Projects under the "OwnerPMC-EPCC" Management Model.

https://kns.cnki.net/kcms/detail/detail.aspx?dbcode= CPFD\&dbname $=$ CPFDLAST2020 \& filename $=$ MQR L201908002046\&v=ja9S0QH8D0a8u9y6FD\%25m md2BiYgQVowvrHuNz7CUfkR0YkEJM6dnhjtvxW WRyh3\%25mmd2FFdJ\%25mmd2FawekNY7YtUgg $\% 3 d$

11. Wang Ning,(2020) Analysis of the Audit Problems of Military Infrastructure Projects under EPC Mode. Accounting Learning, 09:173-175.

12. Cong Xiao-lin,(2011)Research on Principal-agent Mechanism of EPC Mode.

https://kns.cnki.net/kcms/detail/detail.aspx?dbcode= CMFD\&dbname $=$ CMFD2012\& filename $=10120018$

41.nh $\& v=$ Tz00YBZANeza $\% 25 \mathrm{mmd} 2 \mathrm{FJ} 1 \mathrm{mfDduHus}$ UvSO $\% 25 \mathrm{mmd} 2 \mathrm{BD} \% 25 \mathrm{mmd} 2 \mathrm{BwnPkvjqeEACYUv}$ 9mx3Iqeg64sABzccIKBi

13. Zhang Shui-bo, Zhang Lei,(2005) On the Integration of Indicators of Bid Evaluation Under DesignBuild/EPC Project Delivery Approach. Journal of Tianjin University(Social Sciences), 02):97-101.

14. Qiao Dong-yang(2020) Analysis of Owner's Design Management under EPC Mode Based on Project Cases. Project Management. (02):97-101.

15. Yang Jie, Chen Qian(2019)Factors Affecting the Management Performance of EPC Project: A Study Based on Relational Governance. Journal of Engineering Management, 05:109-114.

16. Mao Jia,(2013)Research on Performance Management of EPC Project.

https://kns.cnki.net/kcms/detail/detail.aspx?dbcode $=$ CMFD\&dbname $=$ CMFD201402\& filename $=101417$ 1075.nh\&v $=X \% 25 \mathrm{mmd} 2 \mathrm{FVDDB} 5 \mathrm{reXKsqsmvedrvk}$ cM\%25mmd2F14Ldl8U9w5bWQ8dHgCIOHIR2Oq 7MWFNSJPFUpVUc

17. Daniel L.Stufflebeam, Chris L.S.Coryn.(2019)Evaluation Theory, Model, and Applications Second Edition. National Defense Industry Press, BeiJing. 